\title{
Numerical Investigation of Conjugate Heat Transfer in Rectangular Micro-Channel Heat Sinks under Laminar Flow Conditions
}

\author{
Haluk Anil Kose, Alperen Yildizeli, ${ }^{*}$ Gokhan Canbolat and Sertac Cadirci \\ Department of Mechanical Engineering, Istanbul Technical University, 34337 Istanbul, TR
}

\begin{abstract}
In this study, numerical calculations are performed to investigate steady, laminar convective heat transfer characteristics in rectangular micro channel heat sinks under constant heat fluxes. The investigations are performed at three different inlet Reynolds numbers $(400,600$ and 800$)$ and constant heat fluxes $\left(500,1000\right.$ and $\left.2000 \mathrm{~kW} / \mathrm{m}^{2}\right)$. The aspect ratios of the rectangular micro-channel are selected 1, 1.5 and 2 in the laminar flow regime, respectively. Heat transfer enhancement is the main objective of the study. Nusselt number variation and the pressure drops are found for the given parameters to find the best heat transfer enhancement. It is found that a micro-channel heat sink with square cross-sectional area can be used as an adequate configuration under laminar flow conditions.
\end{abstract}

Key words: Micro-channel Heat Sink, Convective Heat Transfer, CFD

\section{Introduction}

Fluid flow in micro- and mini-channels has been studied by a many researchers over the years. The studies concerning micro-fluidics and micro-scale heat transfer gained popularity among researchers in last decades. To be able to developed the compact systems and reduced material costs the micro-scale configurations need to be designed effectively according to corresponding engineering objectives. Kandlikar [1] classified the micro- and mini-channels by their hydraulic diameter. The micro- and mini-channels have a hydraulic diameter in the range of 50-600 $\mu \mathrm{m}$ and 600-3000 $\mu \mathrm{m}$, respectively. Peng and Petersen [2] investigated single-phase convective heat transfer in micro-channels with various geometric shapes and hydraulic diameters which were found to be an important factor on heat and fluid-flow characteristics. Hetsroni et al. [3] investigated micro-scale heat transfer studies available literature for different hydraulic diameters of circular, rectangular and trapezoidal in the range 101-4010 $\mu \mathrm{m}$ and showed that heat transfer coefficients strictly depend on the shape of the micro-channel and Re numbers.

Naphon and Khonseur [4] studied micro-scale heat transfer and pressure drop under the constant heat fluxes and investigated the effects of Reynolds number, aspect ratio and roughness on heat transfer coefficient and pressure drop. They showed that roughness irregularities oh microchannel walls play a significant role on the heat transfer enhancement and pressure drops. Gunnasegaran et al. [5] investigated heat transfer in micro-channel heat sinks numerically for 3$\mathrm{D}$, steady-state and incompressible water flow using heat sinks of different geometrical shapes and concluded that the smallest hydraulic diameter revealed better performance in terms of heat transfer.

*Corresponding author: G. CANBOLAT Address: Department of Mechanical Engineering, Istanbul Technical University, 34437, İstanbul TURKEY. E-mail address: canbolat17@itu.edu.tr, Phone: (0212) 2931300 
Elshafei et al. [6] investigated pressure drop and convective heat transfer in corrugated microchannels experimentally. Experiments were performed by a constant wall temperature in the laminar flow range and they showed that the friction factor increased with the increasing channel pitch. Qu and Mudavar [7] studied micro-scale conjugate heat transfer and pressure drop for water flow in micro-channel heat sink experimentally and numerically. They found that higher Reynolds numbers are beneficial at reducing both the water outlet temperature and the temperatures within the heat sink, alas at the expense of greater pressure drop. Wang et al. [8] investigated the influence of geometric parameters on flow and heat transfer performance of micro-channel heat sinks. They used micro-channels with different cross-sections and solved conjugate heat transfer and tested the effect of aspect ratio on thermal resistance and heat transfer coefficient. The thermal resistance and pressure drop of rectangular micro-channel heat sink were affected by the channel number.

Sahar et al. [9] carried out CFD analyses to investigate effects of aspect ratio and hydraulic diameter on heat transfer and fluid-flow using constant heat flux from bottom wall and isolated upper wall as thermal boundary conditions. They found that the heat transfer coefficient was not affected by the aspect ratio while Nusselt number increased with the increasing hydraulic diameter. They also showed that the friction also increased with increasing hydraulic diameter. Sahar et al. [10] investigated micro-scale conjugate heat transfer for a single-phase flow both numerically and experimentally. They showed that the 3-D thin-wall simulation showed excellent agreement with the experimental data while 3-D full conjugate model demonstrated significant deviation compared to experimental data due to conjugate effects.

In this study, we investigate the effect of aspect ratios of the micro-channel, the inlet Reynolds numbers and heat fluxes on Nusselt number under laminar flow conditions and conjugate heat transfer. It is found that the inlet Reynolds number has a more dominant effect on increasing the Nusselt number compared to the other parameters.

\section{Materials and Method}

\subsection{Geometry and Mesh}

The configuration of the micro-channel heat sink is shown in Figure 1. In this configuration, the micro-channel cross-sectional area is rectangular where $\mathrm{W}_{\mathrm{c}}$ and $\mathrm{H}_{\mathrm{c}}$ represent the width and height of the cross-sectional area, respectively. In this study, three different aspect ratios of the crosssectional area are selected 1,1.5 and 2 that are represented by $\alpha=H_{c} / W_{c}$. The dimensions of the micro-channel heat sink are given in Table 1 [7] where W, H and L represent the width, height and length of the micro-channel heat sink, respectively.

Table 1. Dimensions of the micro-channel heat sink.

\begin{tabular}{ccc}
\hline $\mathrm{W}(\mathrm{mm})$ & $\mathrm{H}(\mathrm{mm})$ & $\mathrm{L}(\mathrm{mm})$ \\
\hline 10.00 & 7.62 & 44.80 \\
\hline
\end{tabular}




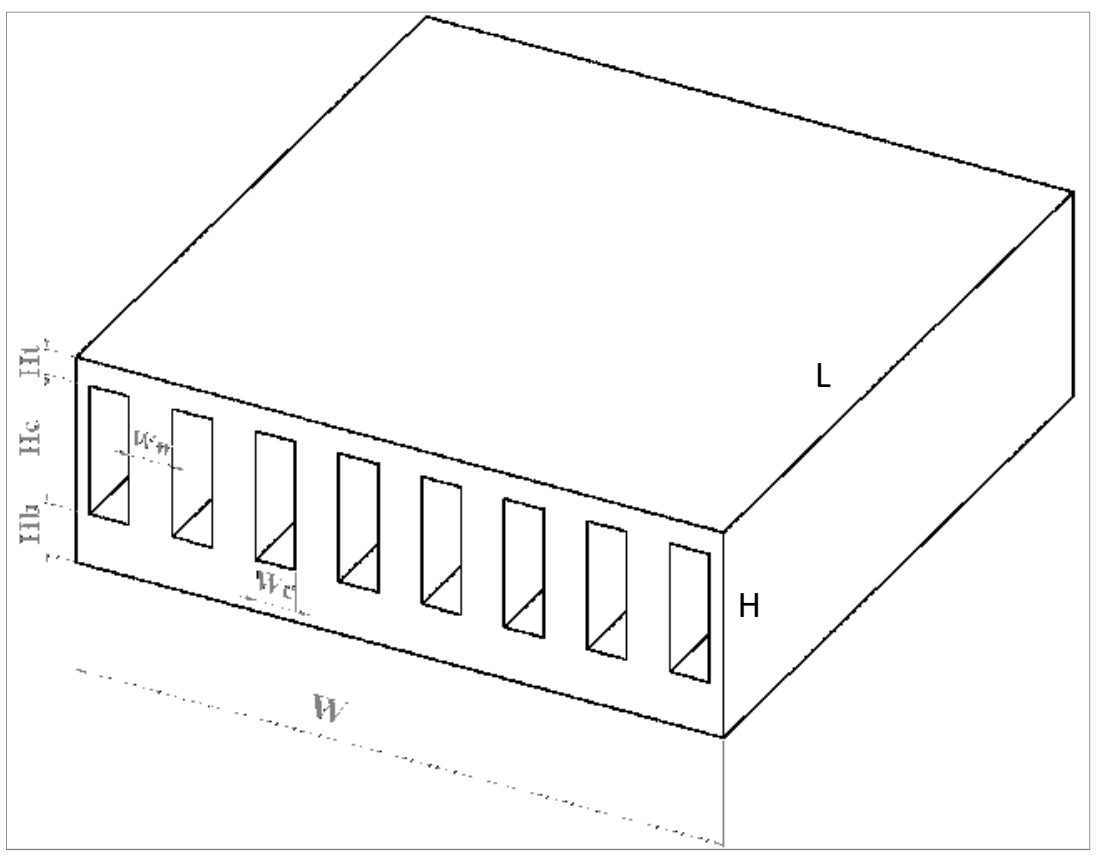

Figure 1. Solid model of the micro-channel heat sink.

While constructing the mesh for computational domain, "structured mesh" is chosen to avoid skewness restrictions. Mesh refinement is done near channel walls. Figure (2a) shows the computational domain of one module with the solid domain with the solid (S) and fluid (F) domains. Figure (2b) shows the details of the structured mesh near the wall.
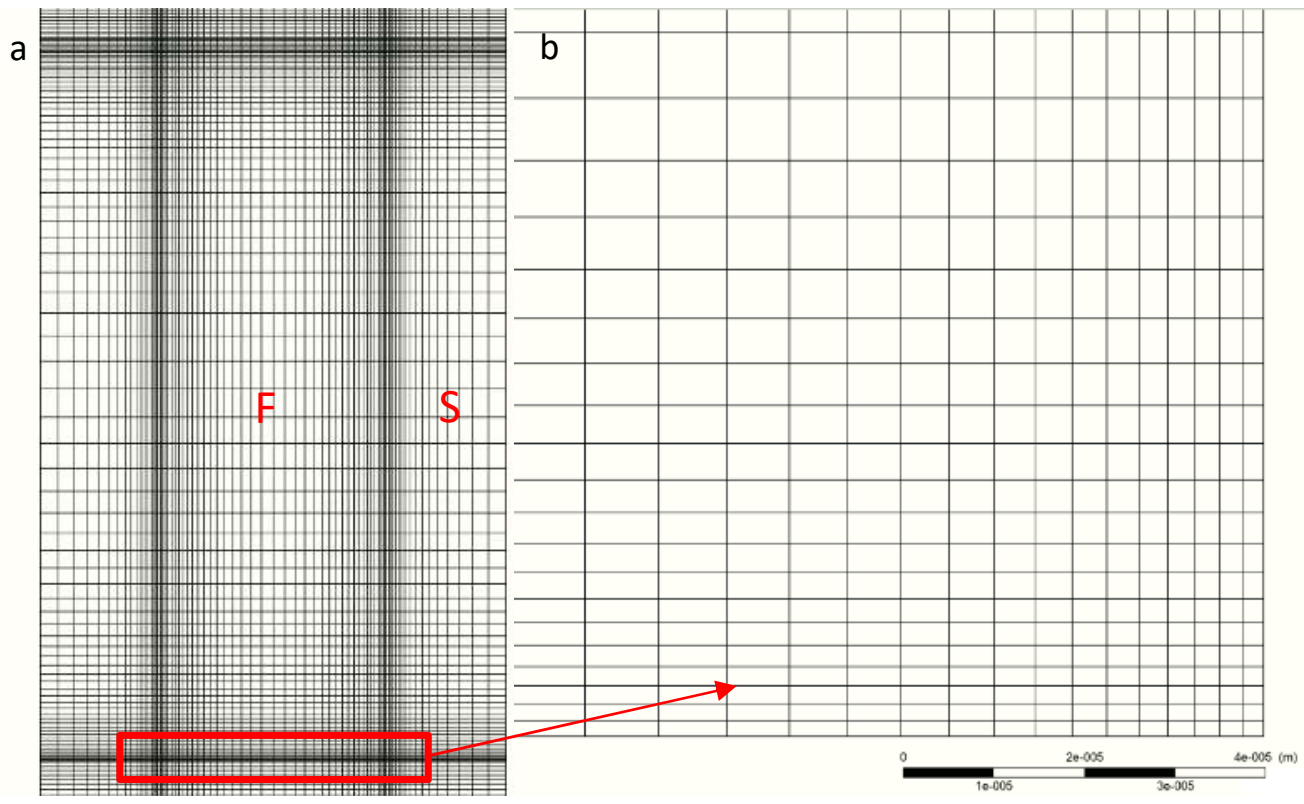

Figure 2. Structured mesh: (a) of one module, (b) in the vicinity of the wall. 
To obtain robust and reliable computational results intensive mesh independency tests are performed for different number of element. During calculations, temperature and pressure differences between the micro-channel inlet and outlet monitored. The pressure drop is assumed to be an indicator of mesh independency. As Figure (3a) shows a mesh consisting of nearly $2.5 \mathrm{M}$ elements is found to be sufficient to carry out CFD calculations. The dimensions of the benchmark case are given in Table 2 and taken from [7].

Table 2. Dimensions of the benchmark micro-channel heat sink [7].

\begin{tabular}{lcccccccc}
\hline Case & $\mathrm{W}_{\mathrm{c}}(\mathrm{mm})$ & $\mathrm{H}_{\mathrm{c}}(\mathrm{mm})$ & $\mathrm{W}_{\mathrm{w}}(\mathrm{mm})$ & $\mathrm{H}_{\mathrm{t}}(\mathrm{mm})$ & $\mathrm{H}_{\mathrm{b}}(\mathrm{mm})$ & $\mathrm{q}\left(\mathrm{W} / \mathrm{cm}^{2}\right)$ & $\alpha$ & $\mathrm{Re}$ \\
\hline Benchmark & 0.231 & 0.713 & 0.236 & 1.270 & 5.637 & 100 & 3.087 & 890 \\
\hline
\end{tabular}

After mesh independency numerical validation is carried out using the formerly determined mesh of the benchmark micro-channel heat sink to compare Nusselt number. As Figure (3b) shows there is a satisfactory agreement between our numerical results and experimental data by Qu and Mudavar [7].
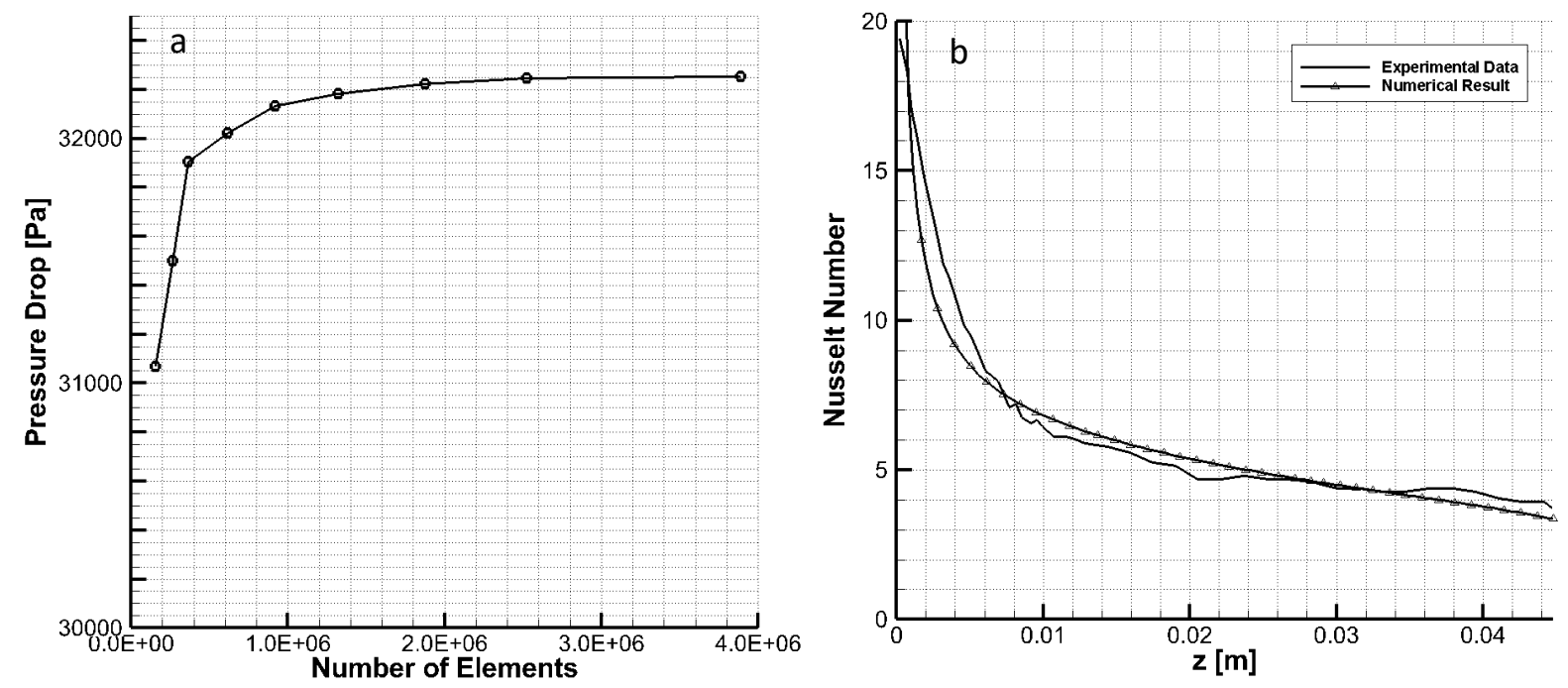

Figure 3. (a) Mesh independency tests and (b) validation by experiment.

In our calculations we used nine configurations tabulated in Table 3. Heat flux is applied from the bottom wall of the heat sink is represent by q the inlet temperature of the fluid is $288.15 \mathrm{~K}$. The inlet velocity of the fluid is determined according to the inlet Reynolds number (Re).

In our calculations we assumed that the viscosity of water is a function of the temperature and used the Equation (1) as mentioned by Kestin et al. [12].

$\log \left\{\frac{\mu(t)}{\mu\left(20^{\circ} C\right)}=\frac{20-t}{t+96}\left\{1.2378-1.303 \times 10^{-3}(20-t)+3.06 \times 10^{-6}(20-t)^{2}+2.55 \times 10^{-8}(20-t)^{3}\right\}\right.$ 
The thermophysical properties of copper and of the fluid at the inlet of the micro-channel are tabulated 4.

Table 3. Dimensions of the micro-channel heat sinks.

\begin{tabular}{ccccccccc}
\hline Case & $\mathrm{W}_{\mathrm{c}}(\mathrm{mm})$ & $\mathrm{H}_{\mathrm{c}}(\mathrm{mm})$ & $\mathrm{W}_{\mathrm{w}}(\mathrm{mm})$ & $\mathrm{H}_{\mathrm{t}}(\mathrm{mm})$ & $\mathrm{H}_{\mathrm{b}}(\mathrm{mm})$ & $\mathrm{q}\left(\mathrm{W} / \mathrm{cm}^{2}\right)$ & $\alpha$ & $\mathrm{Re}$ \\
\hline 1 & 0.349 & 0.349 & 0.118 & 1.634 & 5.637 & 100 & 1 & 890 \\
2 & 0.290 & 0.436 & 0.177 & 1.547 & 5.637 & 100 & 1.5 & 890 \\
3 & 0.261 & 0.523 & 0.260 & 1.73 & 5.637 & 100 & 2 & 890 \\
4 & 0.349 & 0.349 & 0.118 & 1.634 & 5.637 & 100 & 1 & 400 \\
5 & 0.349 & 0.349 & 0.118 & 1.634 & 5.637 & 100 & 1 & 600 \\
6 & 0.349 & 0.349 & 0.118 & 1.634 & 5.637 & 100 & 1 & 800 \\
7 & 0.349 & 0.349 & 0.118 & 1.634 & 5.637 & 50 & 1 & 800 \\
8 & 0.349 & 0.349 & 0.118 & 1.634 & 5.637 & 100 & 1 & 800 \\
9 & 0.349 & 0.349 & 0.118 & 1.634 & 5.637 & 200 & 1 & 800 \\
\hline
\end{tabular}

Table 4. Thermophysical properties of copper and of water at inlet condition.

\begin{tabular}{lccc}
\hline Materials & $\begin{array}{c}\text { Density } \\
\left(\mathrm{kg} / \mathrm{m}^{3}\right)\end{array}$ & $\begin{array}{c}\text { Thermal Conductivity } \\
(\mathrm{W} / \mathrm{mK})\end{array}$ & $\begin{array}{c}\text { Specific Heat } \\
(\mathrm{J} / \mathrm{kgK})\end{array}$ \\
\hline Copper & 899 & 401 & 385 \\
Water & 1000 & 0.6 & 4178 \\
\hline
\end{tabular}

\subsection{Numerical Approach and Assumptions}

In the numerical modelling a conjugated heat transfer problem is solved. The flow is $3 \mathrm{D}$, laminar, steady and incompressible. The governing equations are conservation of mass, momentum, and energy that are given in Equations (2), (3) and (4), respectively.

$\frac{\partial u}{\partial x}+\frac{\partial v}{\partial y}+\frac{\partial w}{\partial z}=0$

$\rho_{f}\left(u \frac{\partial u}{\partial x}+v \frac{\partial u}{\partial y}+w \frac{\partial u}{\partial z}\right)=-\frac{\partial p}{\partial x}+\mu\left(\frac{\partial^{2} u}{\partial x^{2}}+\frac{\partial^{2} u}{\partial y^{2}}+\frac{\partial^{2} u}{\partial z^{2}}\right)$

$\rho_{f}\left(u \frac{\partial v}{\partial x}+v \frac{\partial v}{\partial y}+w \frac{\partial v}{\partial z}\right)=-\frac{\partial p}{\partial y}+\mu\left(\frac{\partial^{2} v}{\partial x^{2}}+\frac{\partial^{2} v}{\partial y^{2}}+\frac{\partial^{2} v}{\partial z^{2}}\right)$

$\rho_{f}\left(u \frac{\partial w}{\partial x}+v \frac{\partial w}{\partial y}+w \frac{\partial w}{\partial z}\right)=-\frac{\partial p}{\partial z}+\mu\left(\frac{\partial^{2} w}{\partial x^{2}}+\frac{\partial^{2} w}{\partial y^{2}}+\frac{\partial^{2} w}{\partial z^{2}}\right)$

$\rho_{f} c_{p}\left(u \frac{\partial T}{\partial x}+v \frac{\partial T}{\partial y}+w \frac{\partial T}{\partial z}\right)=k_{f}\left(\frac{\partial^{2} T}{\partial x^{2}}+\frac{\partial^{2} T}{\partial y^{2}}+\frac{\partial^{2} T}{\partial z^{2}}\right)$

$\frac{\partial^{2} T_{s}}{\partial x^{2}}+\frac{\partial^{2} T_{s}}{\partial y^{2}}+\frac{\partial^{2} T_{s}}{\partial z^{2}}=0$ 
In Eq. (2) $u, v$ and $w$ are velocity components in $\mathrm{x}-\mathrm{y}$ and $\mathrm{z}$-directions, respectively and pressure is denoted by $p$. The density $\rho_{f}$ and thermal conductivity $k_{f}$ of water is assumed to be constant (see Table 4) and the dynamic viscosity of water $\mu$ at inlet condition is taken $10^{-3} \mathrm{~kg} / \mathrm{ms}$. In Eq.(3) $c_{p}$ is the specific heat and $T$ and $T_{s}$ stand for temperatures of fluid and solid, respectively.

The boundary conditions are specified as follows:

1. No slip conditions on the walls,

2. Uniform velocity profile at the inlet of the micro-channel,

3. Pressure outlet conditions at the outlet of the micro-channel,

4. All walls are insulated except the bottom wall on which a constant heat flux applied.

5. Uniform fluid's temperature $(288.15 \mathrm{~K})$ at the inlet of the micro-channel,

6. Conjugated heat transfer is solved.

The inlet velocity is determined based on the Reynolds number where a hydraulic diameter is defined as characteristic length. The calculations are carried out with SIMPLEC algorithm in ANSYS-Fluent flow solver. The iterations are continued until the residuals of velocity, continuity and energy converged to $10^{-6}, 10^{-5}$ and $10^{-7}$, respectively.

\section{Results}

The numerical results are obtained from configurations given in Table 3 where the hydraulic diameter is the same for all cases that is calculated from the benchmark case with the dimension in Table 2. The numerical results are evaluated according to Nusselt number variation in streamwise direction that is obtained from various aspect ratios, inlet Reynolds numbers and bottom heat fluxes. The local heat transfer coefficient of the micro-channel and local Nusselt number are defined in Equations (5) and (6), respectively. In Eq. (5) $A_{b}$ stands for bottom heating area of the heat sink substrate and $T_{\mathrm{w}}(\mathrm{y})$ in Eq. (7) and $T_{\mathrm{f}}(\mathrm{y})$ in Eq. (8) are the local wall temperatures and local bulk fluid temperature along flow direction, respectively [8].

$$
\begin{aligned}
& h(y)= \frac{q L W}{A_{b}\left[T_{W}(y)-T_{f}(y)\right]} \\
& N u(y)= \frac{h(y) D_{h}}{k_{f}} \\
& T_{w}(y)= \frac{1}{W_{c}} \int_{W_{c}} T_{W}\left(x, y, H_{b}\right) d x \\
& T_{f}(y)= \frac{1}{W_{c} H_{c}} \int_{H_{b}}^{H_{c}} \int_{0}^{W_{c}} \rho u(x, y, z) \mathrm{c}_{\mathrm{p}} T_{f}(x, y, z) d x d z \\
& \frac{1}{W_{c} H_{c}} \int_{H_{b}}^{H_{c} W_{c}} \rho \mathrm{c}_{\mathrm{p}} u(x, y, z) d x d z
\end{aligned}
$$




\subsection{Effect of Aspect Ratio}

While examining the effect of the aspect ratio $\alpha$, the heat flux at the bottom of the substrate is taken $100 \mathrm{~W} / \mathrm{cm}^{2}$ and inlet Reynolds number is 890 . Figure (4a) demonstrates the effect of $\alpha$ for the first three cases. The highest local Nusselt number can be obtained for the case of square cross-sectional area compared to other two cases. On the other hand, among this three cases highest pressure drop achieve for $\alpha=2$ as tabulated in Table 5. Based on this remarkable argument about heat transfer enhancement other remaining six cases $\alpha$ is taken 1 .

\subsection{Effect of Reynolds Number}

While examining the effect of the inlet Re, the heat flux at the bottom of the substrate is taken $100 \mathrm{~W} / \mathrm{cm}^{2}$ and $\alpha$ is taken 1 . As Figure (4b) shows local $\mathrm{Nu}$ variation among this three cases (45-6) obtained. However, despite the heat transfer enhancement at $\mathrm{Re}=800$, the highest pressure drop is encountered in this case. This can be explained that for the cases $\mathrm{Re}=800$ higher mass flow rate is pumped into the micro-channel which causes higher friction loses in connection with pressure drop. As a results for this investigation the remaining analyses are done for $\mathrm{Re}=800$.
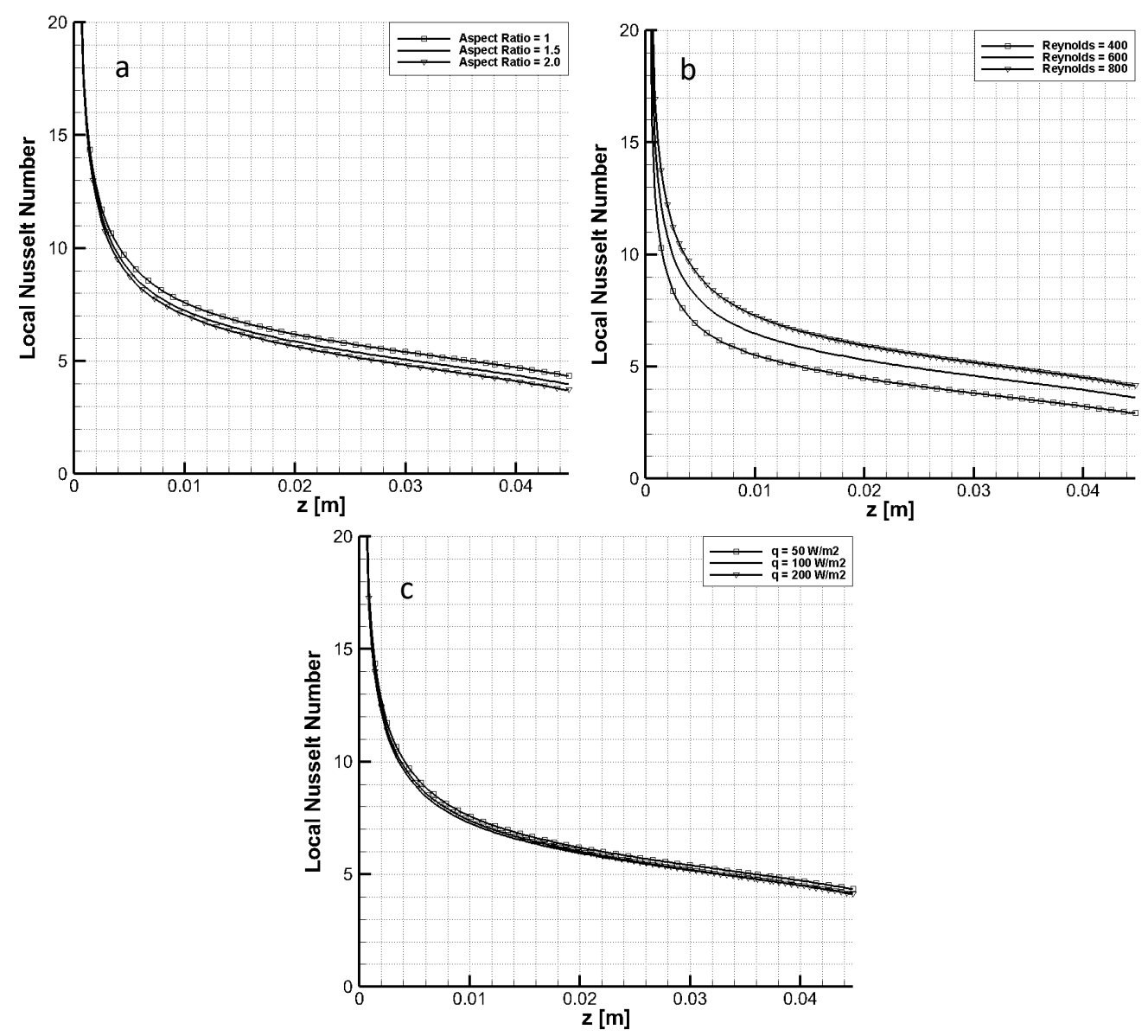

Figure 4. Local $\mathrm{Nu}$ variation for various (a) $\alpha$, (b) Re and (c) heat flux 


\subsection{Effect of Heat Flux}

If three heat fluxes are applied at the bottom of the substrate, the local Nu number is not affected whereas the pressure drop is decreased with increasing heat flux as a result of decreasing dynamic viscosity with temperature in Eq. (1) as shown in Figure (4c).

Figure 5 shows temperature contours in flow direction on 2-D slices extracted along microchannel. The temperature distribution for the conjugate heat transfer problem is not considerably affected by the aspect ratio since the heat fluxes at the bottom of substrate and the inlet Re are the same as shown in Figure (5a). If the effect of the inlet Re is investigated for the same $\alpha$ and heat flux, it can be seen that the conjugated heat transfer near the outlet of micro-channel is better at the higher Reynolds number and heat is conducted to the fluid more effectively so that a uniform temperature distribution can be achieved as given in Figure (5b). A final investigation is done for increasing heat flux at the same $\alpha$ and inlet Re. As Figure (5c) indicates heat is stored in the solid substrate most efficiently at the highest heat flux.
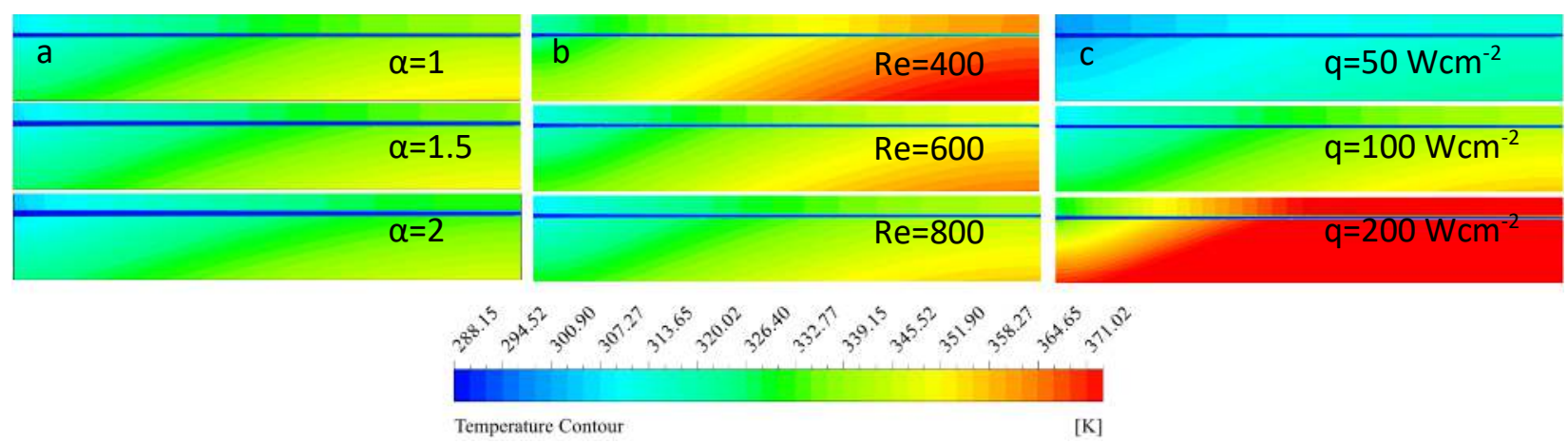

Figure 5. Temperature contours in flow direction: (a) Re=890 and $\mathrm{q}=100 \mathrm{~W} / \mathrm{cm}^{2}$ (b) $\alpha=1$ and $\mathrm{q}=100 \mathrm{~W} / \mathrm{cm}^{2}$ (c) $\alpha=1$ and $\mathrm{Re}=800$.

Table 1. Pressure drop comparisons for all cases

\begin{tabular}{cccc}
\hline$\alpha$ & $\mathrm{Re}$ & $\mathrm{q}\left[\mathrm{W} / \mathrm{cm}^{2}\right]$ & $\Delta \mathrm{P}[\mathrm{kPa}]$ \\
\hline 1 & 890 & 100 & 26.7 \\
1.5 & 890 & 100 & 27.5 \\
2 & 890 & 100 & 29.0 \\
1 & 400 & 100 & 9.9 \\
1 & 600 & 100 & 16.4 \\
1 & 800 & 100 & 23.4 \\
1 & 800 & 50 & 25.7 \\
1 & 800 & 100 & 23.4 \\
1 & 800 & 200 & 20.7 \\
\hline
\end{tabular}

\section{Conclusion}

In this numerical study, a conjugated heat transfer in micro-channel heat sinks is modelled numerically under laminar flow conditions considering the viscosity of the fluid as a function of 
temperature. The effects of the micro-channel's aspect ratio, inlet Re and bottom heat flux on the variation of local $\mathrm{Nu}$ and pressure drop are investigated independently. It is found that the inlet Re has a more dominant effect than the other parameters in terms of heat transfer enhancement under the same conditions. Future works can include investigation of micro-channels with different geometrical shapes such as trapezoidal or triangular cross-sections and optimization of both heat transfer and the pumping power requirement. Furthermore, influence of the channel number on the thermal resistance and pressure drop under the same conditions can be investigated and optimized.

\section{References}

[1] S.G. Kandlikar, Two-phase flow patterns, pressure drop and heat transfer during boiling in mini-channel and micro-channel flow passages of compact heat exchangers. In: Compact Heat Exchangers and Enhancement Technology for the Process Industries, Begell House, New York, 2001, pp. 319-334.

[2] Peng, X. F., \& Peterson, G. P. (1996). Convective heat transfer and flow friction for water flow in microchannel structures. International Journal of Heat and Mass Transfer, 39(12), 25992608.

[3] Hetsroni, G., Mosyak, A., Pogrebnyak, E., \& Yarin, L. P. (2005). Fluid flow in microchannels. International Journal of Heat and Mass Transfer, 48(10), 1982-1998.

[4] Naphon, P., \& Khonseur, O. (2009). Study on the convective heat transfer and pressure drop in the micro-channel heat sink. International Communications in Heat and Mass Transfer, 36(1), 39-44.

[5] Gunnasegaran, P., Mohammed, H. A., Shuaib, N. H., \& Saidur, R. (2010). The effect of geometrical parameters on heat transfer characteristics of microchannels heat sink with different shapes. International Communications in Heat and Mass Transfer, 37(8), 1078-1086.

[6] Elshafei, E. A. M., Awad, M. M., El-Negiry, E., \& Ali, A. G. (2009). Heat transfer and pressure drop in corrugated channels. Energy, 35(1), 101-110.

[7] Qu, W. L., \& Mudawar, I. (2002). Experimental and numerical study of pressure drop and heat transfer in a single-phase micro-channel heat sink. International Journal of Heat and Mass Transfer, 45(12), 2549-2565.

[8] Wang, H Wang, H., Chen, Z., \& Gao, J. (2016). Influence of geometric parameters on flow and heat transfer performance of micro-channel heat sinks, 107, 870-879.

[9] Sahar, A. M., Wissink, J., Mahmoud, M. M., Karayiannis, T. G., \& Ashrul Ishak, M. S. (2017). Effect of hydraulic diameter and aspect ratio on single phase flow and heat transfer in a rectangular microchannel. Applied Thermal Engineering, 115, 793-814. 
[10] Sahar, A. M., Ozdemir, M. R., Fayyadh, E. M., Wissink, J., Mahmoud, M. M., \& Karayiannis, T. G. (2016). Single phase flow pressure drop and heat transfer in rectangular metallic microchannels. Applied Thermal Engineering, 93, 1324-1336.

[11] Hetsroni, G., Mosyak, A., Pogrebnyak, E., \& Yarin, L. P. (2005). Fluid flow in microchannels. International Journal of Heat and Mass Transfer, 48(10), 1982-1998.

[12] Kestin, J., Sokolov, M., \& Wakeham, W. A. (1978). Viscosity of liquid water in the range Journal of Physical and Chemical Reference Data, 7(3), 941-948. 